PAPER

Ultrafast scanning calorimetry of newly developed Au-Ga bulk metallic glasses

To cite this article: Nico Neuber et al 2020 J. Phys.: Condens. Matter 32324001

View the article online for updates and enhancements.

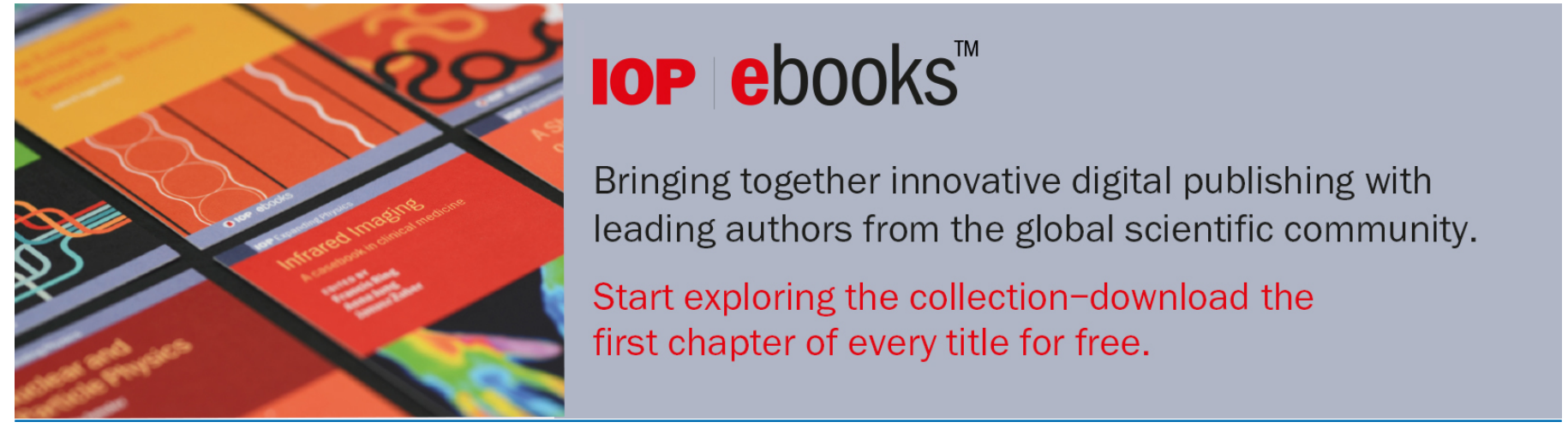

This content was downloaded from IP address 134.96 .58 .39 on 14/05/2020 at 09:04 


\title{
Ultrafast scanning calorimetry of newly developed Au-Ga bulk metallic glasses
}

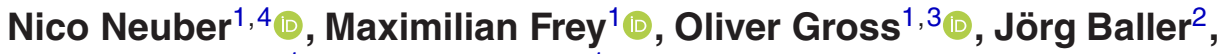 \\ Isabella Gallino ${ }^{1}$ and Ralf Busch ${ }^{1}$ \\ ${ }^{1}$ Chair of Metallic Materials, Saarland University, Campus C6.3, 66123 Saarbrücken, Germany \\ 2 Physics and Materials Science Research Unit, University of Luxembourg, 162a, Avenue de la Faïencerie, \\ L-1511, Luxembourg \\ 3 Amorphous Metal Solutions GmbH, Homburg, Germany
}

Received 13 January 2020, revised 28 February 2020

Accepted for publication 23 March 2020

Published 12 May 2020

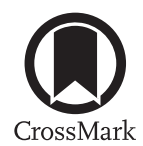

\begin{abstract}
The isothermal crystallization times and critical cooling rates of the liquid phase are determined for the two bulk metallic glass forming alloys $\mathrm{Au}_{49} \mathrm{Ag}_{5.5} \mathrm{Pd}_{2.3} \mathrm{Cu}_{26.9} \mathrm{Si}_{16.3}$ and $\mathrm{Au}_{51.6} \mathrm{Ag}_{5.8} \mathrm{Pd}_{2.4} \mathrm{Cu}_{20.2} \mathrm{Ga}_{6.7} \mathrm{Si}_{13.3}$ by using fast differential scanning calorimetry, covering the whole timescale of the crystallization event of the metallic melt. In the case of $\mathrm{Au}_{49} \mathrm{Ag}_{5.5} \mathrm{Pd}_{2.3} \mathrm{Cu}_{26.9} \mathrm{Si}_{16.3}$, a typical crystallization nose was observed, whereas for the $\mathrm{Au}_{51.6} \mathrm{Ag}_{5.8} \mathrm{Pd}_{2.4} \mathrm{Cu}_{20.2} \mathrm{Ga}_{6.7} \mathrm{Si}_{13.3}$, a more complex crystallization behavior with two distinct crystallization noses was found. Even for the complex crystallization behavior of the $\mathrm{Au}_{51.6} \mathrm{Ag}_{5.8} \mathrm{Pd}_{2.4} \mathrm{Cu}_{20.2} \mathrm{Ga}_{6.7} \mathrm{Si}_{13.3}$ alloy it is shown that the minimal isothermal nose time $\tau_{x}^{*}$ does allow for a quantification of the macroscopic critical thickness. It is discussed in contrast to the critical cooling rate, which is found to allow less exact calculations of the critical thickness and thus does not correlate well with the critical cooling rate from macroscopic experiments. Additionally the crystallization data of $\mathrm{Au}_{49} \mathrm{Ag}_{5.5} \mathrm{Pd}_{2.3} \mathrm{Cu}_{26.9} \mathrm{Si}_{16.3}$ was modeled using classical nucleation theory with the Johnson-Mehl-Avrami-Kolmogorov (JMAK) equation, enabling a determination of the interfacial energy.
\end{abstract}

Keywords: amorphous metal, crystallization, fast scanning calorimetry, interfacial energy, noble metal

S. Supplementary material for this article is available online

(Some figures may appear in colour only in the online journal)

\section{Introduction}

In 2005, the $18 \mathrm{~K}$ gold-based bulk metallic glass (BMG) alloy with the composition $\mathrm{Au}_{49} \mathrm{Ag}_{5.5} \mathrm{Pd}_{2.3} \mathrm{Cu}_{26.9} \mathrm{Si}_{16.3}$ (Au-BMG) was published by $\mathrm{W}$ L Johnson and co-workers [1]. Its premium white color and high hardness (360 HV5) in the ascast state made it appealing for jewelry applications on the first sight, but a tremendous room-temperature tarnishing soon foiled the commercial applicability of the material $[2,3]$. Hence, the alloy became the focus of alloy development, to address its non-desirable fast tarnishing kinetics. Strong effort by different groups was put into modifications of the basic $\mathrm{Au}-\mathrm{Cu}-\mathrm{Si}$ system or into the exploration of new Au-based

${ }^{4}$ The author to whom any correspondence should be addressed. systems to improve the corrosion behavior $[4,5]$. One applied strategy was based on partially substituting $\mathrm{Cu}$ with $\mathrm{Ga}$, followed by an adjustment of the $\mathrm{Au}-\mathrm{Si}$ ratio, leading to a reduction of tarnishing, but also a decrease of glass forming ability (GFA). Ultimately, the new Ga containing alloys show reduced changes in color through corrosive processes. Its initial white color only changes over time to a slight rose color, instead of a non-appealing dark-red, while still possessing the, compared to crystalline $18 \mathrm{~K} \mathrm{Au}$ alloys, superior mechanical properties (see SI-table I). Therefore it marks an alloy that could finally be used in jewelry applications [6].

Regarding the GFA of the AuGa alloy, a beneficial kinetic slow-down through these adjustment was observed and the reduction in GFA was traced back to thermodynamic origins 
[7]. The reduction in glass-forming ability of the Gacontaining alloy has somehow to translate to the TTT-diagram. A reduction in GFA initially suggests a shift of the crystallization nose to shorter times. An alteration of the overall shape of the nose, which is governed by the thermodynamic and kinetic properties that are known to have changed, is expected. The exact knowledge of these changes in the TTT diagram may allow a deeper understanding of the different behavior of the AuGa alloy.

In this study the initial alloy $\mathrm{Au}_{49} \mathrm{Ag}_{5.5} \mathrm{Pd}_{2.3} \mathrm{Cu}_{26.9} \mathrm{Si}_{16.3}$ (Au-BMG) and the modified Ga-containing alloy $\mathrm{Au}_{51.6} \mathrm{Ag}_{5.8} \mathrm{Pd}_{2.4} \mathrm{Cu}_{20.2} \mathrm{Ga}_{6.7} \mathrm{Si}_{13.3}$ (AuGa-BMG) are examined using fast differential scanning calorimetry (FDSC) to determine the isothermal temperature transformation (TTT) diagram. The isothermal crystallization data allow to assess the interfacial energy $\gamma_{1-x}$ between the crystalline and liquid phase by using the Johnson-Mehl-Avrami-Kolmogorov equation [8,9]. This technique was already successfully applied to fit TTT measurements obtained by conventional differential scanning calorimetry (DSC) [10].

The new technique of FDSC allows to measure the full TTT diagram upon cooling, including the fastest crystallization processes at the minimum crystallization time $\tau_{x}^{*}$. This time is represented by the tip of the typical TTT-nose, resulting from the interplay of fast crystallization growth rate and high nucleation rate. Without FDSC this region was only experimentally accessible in extremely good glass formers and/or in complex container-less experiments that excluded heterogeneous nucleation [11-16].

Due to its low melting point the Au-BMG is often used as a model-system for FDSC studies of BMGs [17, 18]. It is known to show a single crystallization nose, which can be well described by the JMAK model. In contrast the measured TTT diagram for the modified, Ga containing, alloy shows a dramatical change with a remarkable split-up of the crystallization nose. A comparable split up was already observed in FDSC for polymers [19]. This new nose may be accountable to a new crystalline phase originating from the additional $\mathrm{Ga}$ in the system.

\section{Experimentals}

The master alloys of $\mathrm{Au}_{49} \mathrm{Ag}_{5.5} \mathrm{Pd}_{2.3} \mathrm{Cu}_{26.9} \mathrm{Si}_{16.3}$ (Au-BMG) and $\mathrm{Au}_{51.6} \mathrm{Ag}_{5.8} \mathrm{Pd}_{2.4} \mathrm{Cu}_{20.2} \mathrm{Ga}_{6.7} \mathrm{Si}_{13.3}$ (AuGa-BMG) were produced by inductive melting of the pure elements (purity $>99.95 \%$ ) in a $\mathrm{ZrO}_{2}$ coated $\mathrm{Al}_{2} \mathrm{O}_{3}$ crucible under a high purity argon atmosphere (vacuum ca. $5 \times 10^{-3}$ mbar prior filling with Ar containing $\sim 0.5 \mathrm{ppm}$ oxygen) in a modified MC15 INDUTHERM tilt-casting device. After the melting, the material was tilt-cast into water-cooled copper molds. To maintain a high homogeneity on the microscopic scale, the samples were cast to $\mathrm{x}$-ray-amorphous rods with $3 \mathrm{~mm}$ of diameter. Afterwards the rods were used in a self-built melt-spinning device, to produce thin ribbons with thickness of about $20 \mu \mathrm{m}$ and width of $2 \mathrm{~mm}$. The amorphous nature of the ribbons was validated by x-ray diffraction (see SI figure V). From these ribbons small FDSC samples were cut-off using a micro-scalpel.
The FDSC measurements were carried out with a Mettler Toledo Flash DSC 1, which is capable of high heating rates up to $20000 \mathrm{~K} \mathrm{~s}^{-1}$ and cooling rates up to $6000 \mathrm{~K} \mathrm{~s}^{-1}$. For the measurements an intracooler was used to establish a sensor support temperature $T_{\mathrm{ss}}$ of $183 \mathrm{~K}$ to enable the achievement of high cooling rates even at the lower temperature regimes around the glass transition of the given alloys $(\sim 373$ $\mathrm{K}$ ). During the measurement the samples were protected from oxidation with a constant flow of $50 \mathrm{ml} \mathrm{min}^{-1}$ of $\mathrm{N}_{2}$.

The liquidus temperatures $T_{1}$ of the used alloys are $664 \mathrm{~K}$ (Au-BMG) and $679 \mathrm{~K}$ (AuGa-BMG), which are well below the maximum allowed temperature of the FDSC, allowing a melting and re-vitrification of the alloys on the chip of the calorimeter. This technique enables multiple measurements of the same sample. In order to re-obtain the glassy state of the sample, after crystallization has occurred, the samples are reheated to a temperature around $50 \mathrm{~K}$ above their liquidus temperature and held there for $10 \mathrm{~s}$. Subsequently, they are quenched with a cooling rate of $6000 \mathrm{~K} \mathrm{~s}^{-1}$. In order to bypass the crystallization a certain overheating and holding time, well above the liquidus temperature, is crucial to dissolve species-specific nuclei in the melt $[18,20]$. These species-specific nuclei are arbitrarily ordered residuals of the crystalline lattice that need temperature and time to dissolve, as they otherwise act as heterogeneous nucleation sides that deteriorate the GFA of the liquid [20], resulting in an alteration of the shape of the TTT diagram [18]. For that reason it is also crucial to overheat the melt well above their liquidus temperature in macroscopic casting processes.

The sample mass was calculated from the measured enthalpy of fusion in FDSC, using the enthalpy of fusion priorly determined in a conventional DSC, as described in reference $[21,22]$. Based on this a sample mass of $\sim 1.9 \mu \mathrm{g}$ for $\mathrm{Au}_{49} \mathrm{Ag}_{5.5} \mathrm{Pd}_{2.3} \mathrm{Cu}_{26.9} \mathrm{Si}_{16.3}$ (Au-BMG) and $\sim 1.4 \mu \mathrm{g}$ for $\mathrm{Au}_{51.6} \mathrm{Ag}_{5.8} \mathrm{Pd}_{2.4} \mathrm{Cu}_{20.2} \mathrm{Ga}_{6.7} \mathrm{Si}_{13.3}$ (AuGa-BMG) was calculated. According to reference [21] the used masses should not influence the critical cooling rate (CCR). It shall be noted that an explicit calculation of the thermal lag is consciously excluded, as we waive the determination of explicit temperatures from fast scans. In this study only isothermal measurements as well as scans with $50 \mathrm{~K} \mathrm{~s}^{-1}$ are used, which are found well below the rates where a typical influence of the thermal lag is reported for similar alloys and sample size $\left(<1000 \mathrm{~K} \mathrm{~s}^{-1}\right)$ [17].

\section{Results and discussion}

The CCR of each alloy was determined using the enthalpies of crystallization during an up-scan with a fixed heating rate of $50 \mathrm{~K} \mathrm{~s}^{-1}$. Prior to the up-scan the cooling rates from the equilibrium liquid down to room-temperature were variated from 10 to $6000 \mathrm{~K} \mathrm{~s}^{-1}$. The used technique is adapted from reference [22]. The results of these measurements are summarized in figure 1, showing the evolution of the crystallization enthalpy as a function of the previously applied cooling rate on a logarithmic scale. The CCR needed for a constant crystallization enthalpy, which is corresponding to an initially fully amorphous sample, is about $400 \mathrm{~K} \mathrm{~s}^{-1}$ for the Au-BMG and 


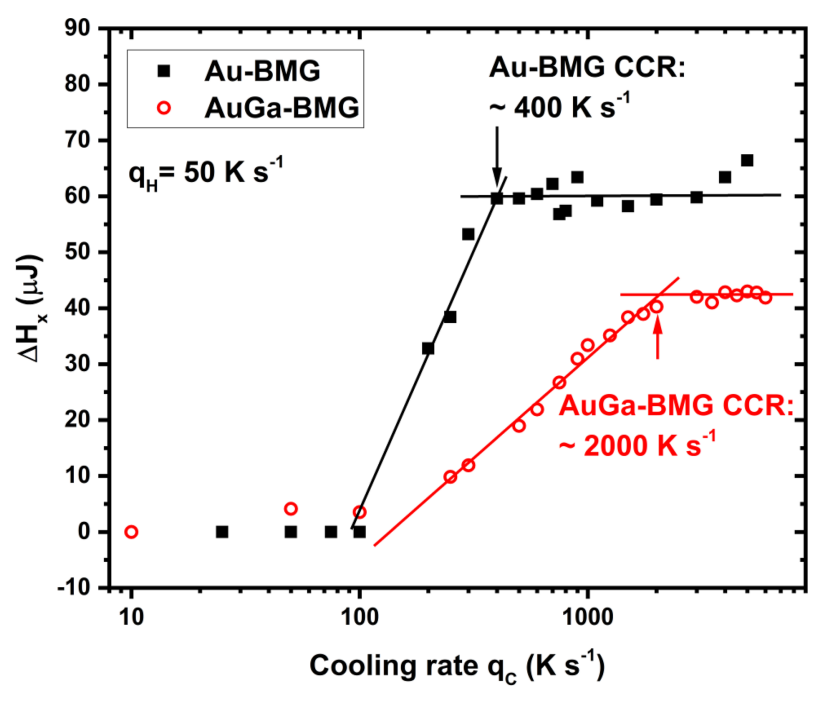

Figure 1. Crystallization enthalpy $\Delta H_{x}$ of $\mathrm{Au}_{49} \mathrm{Ag}_{5.5} \mathrm{Pd}_{2.3} \mathrm{Cu}_{26.9} \mathrm{Si}_{16.3}$ (Au-BMG) and $\mathrm{Au}_{51.6} \mathrm{Ag}_{5.8} \mathrm{Pd}_{2.4} \mathrm{Cu}_{20.2} \mathrm{Ga}_{6.7} \mathrm{Si}_{13.3}$ (AuGa-BMG) over a logarithmic cooling rate. Each enthalpy was determined at a constant heating rate of $50 \mathrm{~K} \mathrm{~s}^{-1}$ after the initial cooling from a temperature well above the liquidus temperature of the respective alloy. The rate, where the plateau value in $\Delta H_{x}$ is reached marks the region, when fully amorphous samples were obtained and thus the critical cooling rate was surpassed. The black and red lines are guides to the eyes.

around $2000 \mathrm{~K} \mathrm{~s}^{-1}$ for the AuGa-BMG. The critical cooling rate is assigned to the intercept of the two guiding lines of the plateau and the slope.

The values for the Au-BMG are in good accordance to the rate of $600 \mathrm{~K} \mathrm{~s}^{-1}$ previously reported by Pogatscher et al [17]. Although, in a study by Perepezko et al a significantly higher CCR of $1100 \mathrm{~K} \mathrm{~s}^{-1}$ is reported for this alloy [22]. A possible explanation for this deviation could be the maximum temperature that was used in the liquid state. Whereas Pogatscher et al use an isothermal holding time of $10 \mathrm{~s}$ at $723 \mathrm{~K}$ comparable to this study, a rather low overheating and no description of isothermal holding time is reported in the manuscript of Perepezko et al. As it was broached in the 'experimentals' section, the lower overheating may lead to a higher number of species-specific nuclei in the melt and therefore created the need of a higher CCR.

In order to compare the determined CCR to the macroscopic critical casting thickness $d_{\mathrm{c}}$ the empirical formula [23]

$$
R_{\mathrm{c}}=\frac{10}{d_{\mathrm{c}}^{2}} \mathrm{~K} \mathrm{~cm}^{2} \mathrm{~s}^{-1},
$$

where $R_{\mathrm{c}}$ is the CCR in $\mathrm{K} \mathrm{s}^{-1}$ and $d_{\mathrm{c}}$ is used in the unit of $\mathrm{cm}$. This equation is derived from basic heat transfer concepts and makes use of standard values of heat capacity and thermal conductivity for metallic melts. Based on the formula and the experimental $d_{\mathrm{c}}(5 \mathrm{~mm}$ for Au-BMG [24] and $3 \mathrm{~mm}$ for the AuGa-BMG [6]) a CCR of $40 \mathrm{~K} \mathrm{~s}^{-1}$ for the Au-BMG and $111 \mathrm{~K} \mathrm{~s}^{-1}$ for the AuGa-BMG would be expected. Despite a correct qualitative trend is observed, it appears that the determination of the CCR in the FDSC does not allow a one by one translation to the macroscopic glass forming ability using this established formula with experimental data of the critical thickness.

The isothermal time-temperature-transformation diagram of the alloy $\mathrm{Au}_{49} \mathrm{Ag}_{5.5} \mathrm{Pd}_{2.3} \mathrm{Cu}_{26.9} \mathrm{Si}_{16.3}$ is depicted in figure 2 . The thermal treatment of the sample consisted of a heating above the liquidus temperature and a holding time of $10 \mathrm{~s}$, followed by quenching at a rate of $6000 \mathrm{~K} \mathrm{~s}^{-1}$ to the desired isothermal temperature. Each isotherm was measured at least three times for statistical reasons. Especially in the hightemperature region above the minimum crystallization time good statistics are needed, as the stochastical nature of the crystallization process becomes more visible in this temperature range. At temperatures close to $T_{1}$ the fast kinetics of the melt result in a fast crystalline growth rate. Thus, if an overcritical nuclei is formed through statistical thermal fluctuations it will lead to a rapid crystallization of the sample. This leads to a sharp and short crystallization event on the one hand, but also to a large deviation in time on the other hand. A diagram, reporting crystallization times of each individual measurement result for both alloys is provided in the SI figure III and IV.

The shape and the times of the observed crystallization nose are aligning well with earlier investigations of the same alloy by Pogatscher et al [17]. One difference is the fact that in this study, below around $500 \mathrm{~K}$, an exothermic event occurs prior to the main crystallization event (see shoulder in heat flow signals in SI figure I). It is marked by red triangles in figure 2. The pre-peak becomes visible in the raw data as a shoulder of the main peak that eventually overlaps with the main crystallization event at high and low temperatures (see SI-figure I). The appearance of such a pre-peak was not analyzed and discussed explicitly in reference [17]. Due to the fact that in reference [17] no raw data of the isothermal crystallization events is shown it remains unclear, whether this event was also appearing in their data or is a new feature in these measurements (figure 2).

Furthermore, isothermal crystallization data acquired in a conventional DSC (Perkin Elmer DSC 8500) in heating from the glassy state is reported in figure 2. Due to the higher time constant of the conventional DSC, the isothermal crystallization events are measured at longer times and consequentially lower temperatures than the FDSC data. For both methods the data and timescales do reasonably well agree with each other. Similar agreements of FDSC and conventional DSC data was already reported on polymer systems [25].

An analogous methodology was carried out for the alloy AuGa-BMG $\left(\mathrm{Au}_{51.6} \mathrm{Ag}_{5.8} \mathrm{Pd}_{2.4} \mathrm{Cu}_{20.2} \mathrm{Ga}_{6.7} \mathrm{Si}_{13.3}\right)$. Here the occurrence of two separated exothermal peaks is observed at every temperature. This points towards a two-step isothermal crystallization process with a faster primary and a slower secondary crystallization (see SI-figure II). The appearance of several steps in the crystallization process is expected since the crystallization in an up-scan with a conventional DSC is also appearing as a four-step process [7]. More surprising is an unexpected shift of the crystallization times between 523 $\mathrm{K}\left(250{ }^{\circ} \mathrm{C}\right)$ and $473 \mathrm{~K}\left(200{ }^{\circ} \mathrm{C}\right)$. In this temperature interval the crystallization becomes re-accelerated, forming a second 


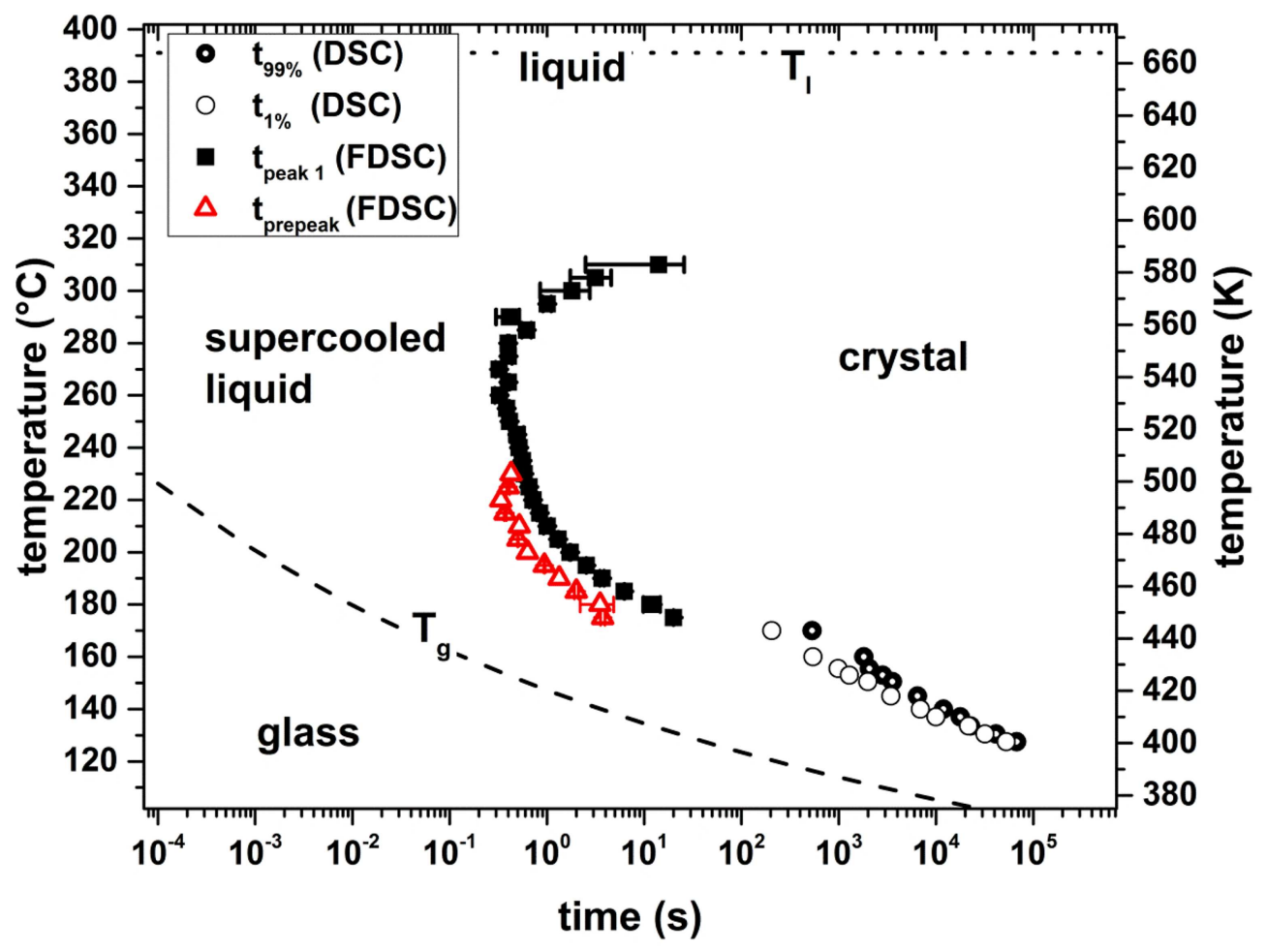

Figure 2. Isothermal time-temperature-transformation (TTT) diagram of $\mathrm{Au}_{49} \mathrm{Ag}_{5.5} \mathrm{Pd}_{2.3} \mathrm{Cu}_{26.9} \mathrm{Si}_{16.3}$ determined in fast differential scanning calorimetry (FDSC) (rectangles and triangles) and conventional DSC (circles).The rate-dependent glass transition temperature is included, based on the Vogel-Fulcher-Tamann fit of kinetic data from reference [7].

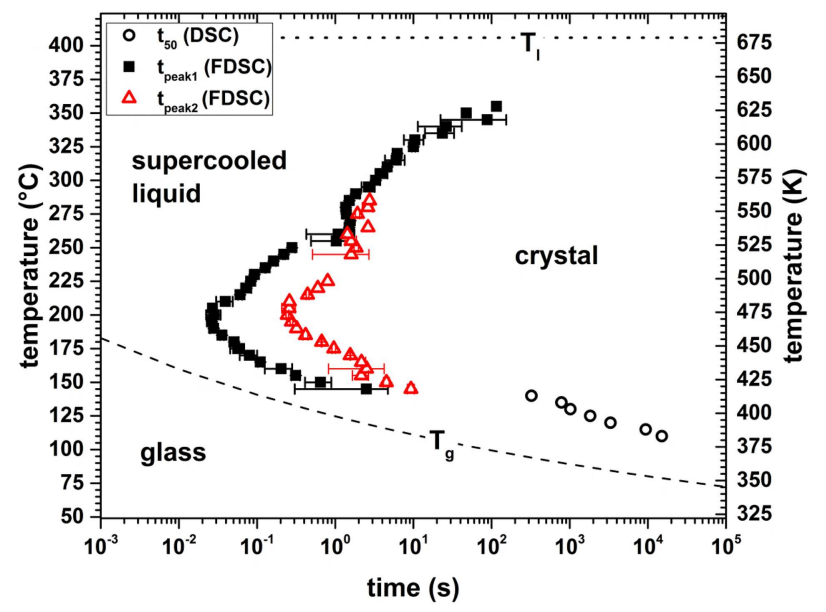

Figure 3. Isothermal time-temperature-transformation (TTT) diagram of $\mathrm{Au}_{51.6} \mathrm{Ag}_{5.8} \mathrm{Pd}_{2.4} \mathrm{Cu}_{20.2} \mathrm{Ga}_{6.7} \mathrm{Si}_{13.3}$ determined in fast differential scanning calorimetry (FDSC) (rectangles and triangles) and conventional DSC (circles). The rate-dependent glass transition temperature is included, based on the Vogel-Fulcher-Tamann fit of kinetic data from reference [7].

nose below the main one. Ultimately, this behavior results in a 'double-nosed' shape of the crystallization nose in the TTT diagram, separating into a slower high temperature crystallization and a, by two magnitudes faster, low temperature crystallization nose. The high and low temperature crystallization is observable for both, the first (black squares) and second crystallization peak (red triangles) alike.
Not only the appearance of this distinct low-temperature nose is unexpected, but also the prominence of it. The fast nature of this process, at such low temperatures relative to the glass transition is rather surprising. Here the kinetics of the liquid phase should have already slowed down significantly to a point that leaves fast crystallization processes improbable. Following this argumentation, the two noses should belong to different crystalline species, each possessing their own crystallization kinetics and especially thermodynamics. Yet, a good alignment to the crystallization times acquired in heating from the glassy state in a conventional DSC can be observed here.

For further analysis the isothermal crystallization data can be used to model the crystallization time as a function of temperature using the JMAK equation:

$$
t(T)=\left[\frac{-3 \ln (1-x)}{\pi I(T)[u(T)]^{3}}\right]^{1 / 4}
$$

where $x$ is the crystalline fraction, $I(T)$ is the nucleation rate given by

$$
I(T)=\frac{A_{\mathrm{v}}}{\eta(T)} \exp \left[\frac{-16 \pi \gamma_{l-x}{ }^{3}}{3 k_{\mathrm{b}} T\left[\Delta G^{l-x}(T)\right]^{2}}\right],
$$

where $A_{\mathrm{v}}$ is a constant, $\gamma_{1-x}$ is the interfacial energy between crystal and liquid phase and $\Delta G^{1-x}$ the difference in Gibbs free energy between the crystalline and liquid phase. $u(t)$ is 
the growth rate expressed as

$$
u(T)=\frac{f k_{\mathrm{b}} T}{3 \pi a_{0}^{2} \eta(T)}\left[1-\exp \left[\frac{n \Delta G^{l-x}(T)}{k_{\mathrm{b}} T}\right]\right],
$$

where $n$ represents the atomic average volume and $a_{0}$ the average atomic diameter. The factor $f$ accounts for the roughness of the interface between crystal and liquid on the atomistic scale. It is assumed to be of unity if $\Delta H_{\mathrm{f}} / T_{1}<2 \mathrm{R}$, resembling a rough interface, which is the case for the observed system. In the case that $\Delta H_{\mathrm{f}} / T_{1}<4 \mathrm{R}$, which is the case of a smooth interface, $f$ would be calculated as $0.2\left(T-T_{1}\right) / T_{1}[26,27]$, where $T_{1}$ is the liquidus temperature, $R$ the universal gas constant and $\Delta H_{\mathrm{f}}$ the enthalpy of fusion.

$I(T)$ and $u(T)$ contain kinetic and thermodynamic contributions that can experimentally be assessed. At first the thermodynamic contribution of the driving force for crystallization that results from the difference in Gibbs free energy between the crystalline and liquid phase $\Delta G^{\mathrm{l}-x}$. It can be calculated from $c_{\mathrm{p}}$ data of the liquid and crystalline state using:

$$
\begin{aligned}
\Delta G^{l-x}(T)=H_{\mathrm{f}} & +\int_{T_{l}}^{T} \Delta c_{\mathrm{p}}^{l-x}\left(T^{\prime}\right) \mathrm{d} T^{\prime} \\
& -T\left(S_{\mathrm{f}}+\int_{T_{l}}^{T} \frac{\Delta C_{\mathrm{p}}^{l-x}\left(T^{\prime}\right)}{T^{\prime}} \mathrm{d} T^{\prime}\right),
\end{aligned}
$$

where $\Delta c_{\mathrm{p}}^{1-x}(T)$ is the excess heat capacity between liquid and crystalline state and $\Delta S_{\mathrm{f}}$ is the entropy of fusion.

The kinetic aspect of glass formation can be characterized by the fragility of the supercooled liquid. Fragility can be expressed by parameters that characterize the equilibrium liquid state, like equilibrium viscosity $\eta$ or relaxation time $\tau$. The temperature dependence of these parameters can be modeled by the empirical Vogel-Fulcher-Tammann equation $(f$ is either $\eta$ or $\tau$, respectively) [28]:

$$
f(T)=f_{0} \exp \left(\frac{D^{*} T_{0}}{T-T_{0}}\right),
$$

where $D^{*}$ represents the fragility parameter and $T_{0}$ is the VFT temperature, at which the function would diverge to infinity. The parameter $f_{0}$ corresponds to the lowest possible value of $\eta$ or $\tau$ at high temperatures.

The description of the kinetic behavior of the examined Au-BMG is actually of a more complex nature, because two different kinetic behaviors of the liquid phase were observed for it. In a quasi-static cooling experiment the occurrence of a polyamorphic liquid-liquid phase transition (LLT) in the system is suggested at $389 \mathrm{~K}$. This means a more fragile hightemperature liquid was observed that eventually transforms to a strong liquid at low temperatures $[29,30]$. In this work, we are studying the crystallization after a cooling from the equilibrium liquid down to isothermal holding temperatures that are found well above the transition temperature (389 K) [29]. Thus, the isothermal crystallization data was modeled with the kinetic data of the fragile liquid. The used thermophysical data

\begin{tabular}{|c|c|}
\hline Fitting parameter & Au-BMG (fragile) \\
\hline$a\left(\mathrm{~J}\right.$ g-atom $\left.{ }^{-1} \mathrm{~K}^{-2}\right)$ & $1.395 \times 10^{-2[b]}$ \\
\hline$b\left(\mathrm{~J} \mathrm{~K} \mathrm{g-atom}{ }^{-1}\right)$ & $2.200 \times 10^{6[\mathrm{~b}]}$ \\
\hline$c\left(\mathrm{~J}\right.$ g-atom $\left.{ }^{-1} \mathrm{~K}^{-2}\right)$ & $-1.43 \times 10^{-2[b]}$ \\
\hline$d\left(\mathrm{~J}\right.$ g-atom $\left.{ }^{-1} \mathrm{~K}^{-3}\right)$ & $4.62 \times 10^{-5[\mathrm{~b}]}$ \\
\hline$\eta_{0}(\mathrm{~Pa} \mathrm{~s})$ & $4 \times 10^{-5}$ \\
\hline$D^{\mathrm{a}}$ & $9.78 \pm 0.4^{[\mathrm{a}]}$ \\
\hline$T_{0}(\mathrm{~K})$ & $311.05 \pm 3.5^{[\mathrm{a}]}$ \\
\hline$T_{\mathrm{liq}}(\mathrm{K})$ & $664^{[\mathrm{c}]}$ \\
\hline$\Delta H_{\mathrm{f}}\left(\mathrm{kJ}\right.$ g-atom $\left.{ }^{-1}\right)$ & $5.2 \pm 0.15^{[\mathrm{c}]}$ \\
\hline$\Delta S_{\mathrm{f}}\left(\mathrm{J}\right.$ g-atom $\left.{ }^{-1} \mathrm{~K}^{-1}\right)$ & $7.83 \pm 0.23^{[\mathrm{c}]}$ \\
\hline$\rho\left(\mathrm{g} \mathrm{cm}^{-3}\right)$ & $13.8 \pm 0.1$ \\
\hline
\end{tabular}
is summarized in table 1 .
Table 1. Summary of the used input parameters for thermodynamic and kinetic modeling for the JMAK fitting.

${ }^{\mathrm{a}}$ References: [a]: [30], [b]: [24], [c]: [6].

In figure 4 the fitted nose is shown together with isothermal data. The model fits very well the upper part of the TTTdiagram and the 'tip' of the crystallization nose. By leaving the interfacial energy $\gamma_{1-x}$ as an open fit-parameter in the model, it can be quantified. The fitting yields an interfacial energy of $0.0474 \pm 0.0009 \mathrm{~J} \mathrm{~m}^{-2}$ and a pre-factor $A_{\mathrm{v}}$ of $3.25 \times 10^{27}$ $\pm 0.41 \times 10^{27}$. The given error only relates to the fitting error, but not the overall error propagation through all the depending properties.

The interfacial energy agrees well with the reported values of $0.052 \mathrm{~J} \mathrm{~m}^{-2}$ for a comparable Au-based system $\left(\mathrm{Au}_{50} \mathrm{Cu}_{25.5} \mathrm{Ag}_{7.5} \mathrm{Si}_{17}\right)$ in reference [31] and a value of 0.039 $\mathrm{J} \mathrm{m}^{-2}$ for $\mathrm{Au}_{49} \mathrm{Ag}_{5.5} \mathrm{Pd}_{2.3} \mathrm{Cu}_{26.9} \mathrm{Si}_{16.3}$ [32]. The latter one being calculated from the FDSC data of Ref [17]. In order to give some relative examples, the interfacial energy of the $\mathrm{Au}-\mathrm{BMG}$ it comparable to that of the Zr-based alloy $\mathrm{Zr}_{41.2} \mathrm{Ti}_{13.8} \mathrm{Cu}_{12.5} \mathrm{Ni}_{10} \mathrm{Be}_{22.5}$ with $0.04 \mathrm{~J} \mathrm{~m}^{-2}$ [33] and is a comparably low value for BMG-forming alloys. But this is not unexpected since the family of Zr-based alloys and the Au-based glass-forming alloys are rather found to be kinetically stabilized [34]. With regard to this an overall scheme on different classes of BMGs can be found in reference [34]. Here bulk metallic glass forming alloys are divided into two different sections: kinetically and thermodynamically stabilized systems, with the latter being subdivided into high interfacial energy and low driving force stabilized systems.

Other noble metal containing bulk metallic glass forming liquids are rather stabilized by their high values of interfacial energy. Namely examples are alloys such as $\mathrm{Pt}_{42.5} \mathrm{Cu}_{27} \mathrm{Ni}_{9.5} \mathrm{P}_{21}$ with a very high value of $0.11 \mathrm{~J} \mathrm{~m}^{-2}$ [34] or $\mathrm{Pt}_{57.3} \mathrm{Cu}_{14.6} \mathrm{Ni}_{5.3} \mathrm{P}_{22.8}$ with $0.086 \mathrm{~J} \mathrm{~m}^{-2}$ [35]. But also Pd-based systems, which are stabilized by a low driving force towards crystallization [36], show higher interfacial energies such as $\mathrm{Pd}_{43} \mathrm{Cu}_{27} \mathrm{Ni}_{10} \mathrm{P}_{20}$ with $0.079 \mathrm{~J} \mathrm{~m}^{-2}$ [15] and $\mathrm{Pd}_{40} \mathrm{Cu}_{30} \mathrm{Ni}_{10} \mathrm{P}_{20}$ with $0.067 \mathrm{~J} \mathrm{~m}^{-2}$ [14].

The given analysis of the interfacial energy was also attempted for the AuGa BMG. However, the complex shape of the double nose prohibits a successful fitting and physically reasonable description based on the nucleation and crystalline 


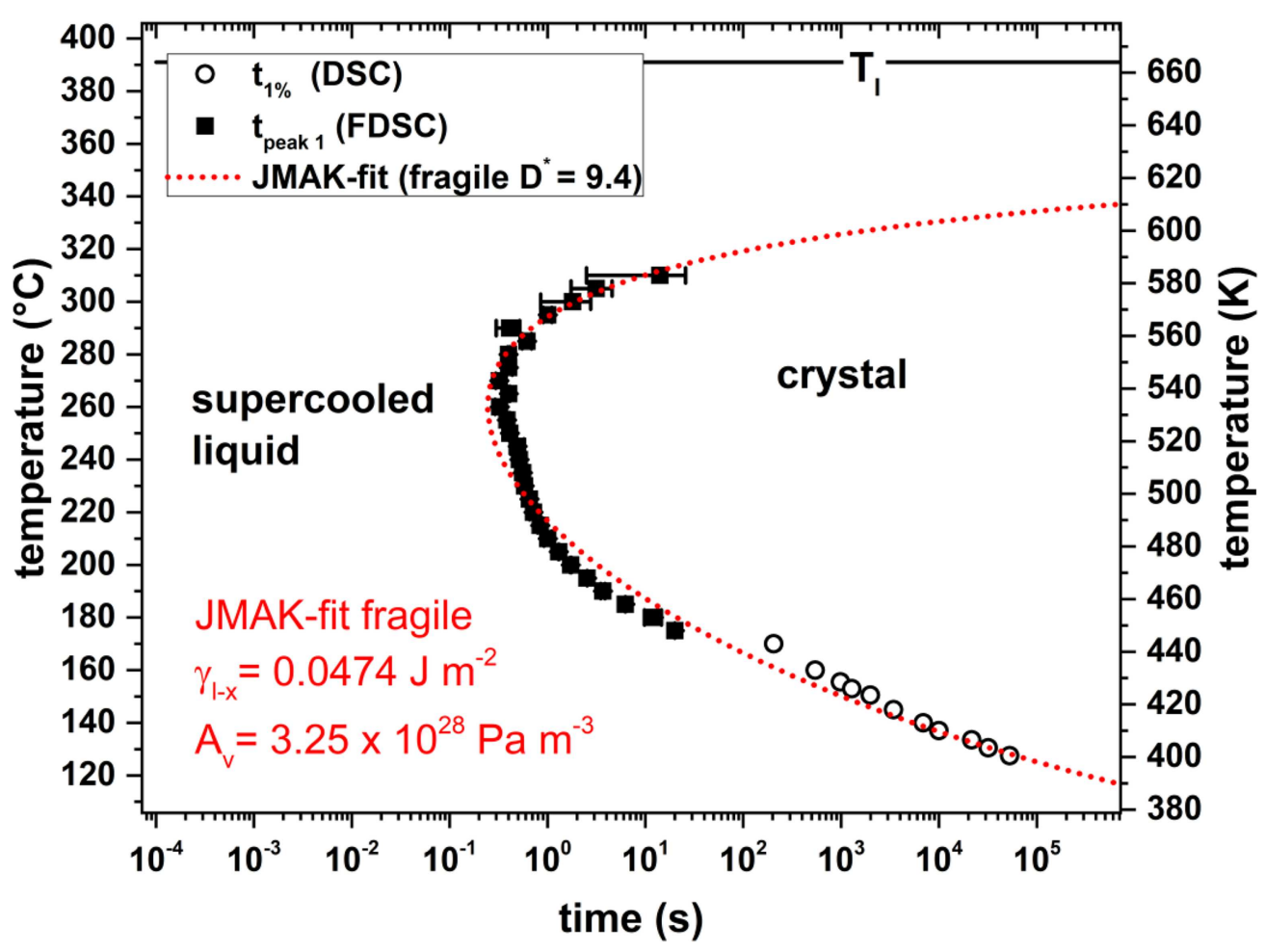

Figure 4. Isothermal crystallization data of the Au-BMG alloy with the Johnson-Mehl-Avrami fitting of the experimental data, based on thermodynamic and kinetic information from references $[6,24,30]$. The JMAK fit is used with the fragile data, as all observed temperatures are found above the possible transition to the strong liquid at $389 \mathrm{~K}$.

growth model provided by the JMAK fit. We suspect an individual analysis of the two crystallization processes will be needed. Especially an understanding of the low-temperature crystallization will be crucial for the correct modeling, as we presume different thermodynamic in-put parameters are needed to be assessed for each crystalline phase. Here the use of FDSC techniques will be needed to determine correct driving forces of crystallization for each species. This is especially important as currently all thermodynamic analysis is based on the crystalline mixture with both crystallization processes being inseparable with conventional thermal analysis techniques.

Nevertheless, does the AuGa-BMG isothermal crystallization data lead to interesting insights. If looking at the lowest crystallization times of both noses, a critical thickness can be estimated by applying the formula

$$
d_{\mathrm{c}}=8.6466\left(\tau_{x}^{*}\right)^{0.394}
$$

where $\tau_{x}^{*}$ marks the minimum crystallization time or also called 'nose time' [37]. This empirical formula, established by Johnson et al, is based on a large database of metallic glass formers. For the detailed study we want to refer to reference [37].

When using the minimum nose time of the high temperature nose of $\tau_{x, \text { high }}^{*}=1.36 \mathrm{~s}$ the equation yields a critical thickness of around $\sim 10 \mathrm{~mm}$. For the lower nose time of $\tau_{x, \text { low }}^{*}=0.026 \mathrm{~s}$ it suggests a critical thickness of $\sim 2 \mathrm{~mm}$. Due to the fact that the $\tau_{x, \text { low }}^{*}$ should determine the GFA a rather good agreement with the experimental critical thickness of $3 \mathrm{~mm}$ is given. The calculation further underlines the role of this second nose on the glass forming ability, deteriorating the GFA from maybe $10 \mathrm{~mm}$ to the observed value. When applying this calculation to the Au-BMG with a nose time of $\tau_{x}^{*}=0.323 \mathrm{~s}$, a critical thickness of $5.5 \mathrm{~mm}$ is calculated, which aligns remarkably good with the experimentally determined critical thickness of $5 \mathrm{~mm}$.

In summary, this suggests that the nose time $\tau_{x}^{*}$ obtained from isothermal crystallization experiments outgoing from the liquid state does provide a vital tool to correlate macroscopic data, e.g. casting experiments, with the FDSC. In contrast, quantitative correlations with the critical cooling rate in macroscopic experiments appeared rather difficult. This circumstance can be possibly traced back to the influence of the low sample size in FDSC with very different volume to surface ratios than in the macroscopic experiment, as well as a lack of massive overheating in the current FDSC setup. But with technical progress, such as the Mettler Toledo FDSC2+, allowing for temperatures up to $1000{ }^{\circ} \mathrm{C}$, at least the lack of overheating could be eliminated for many materials.

\section{Conclusion}

The critical cooling rates (CCR) as well as the isothermal crystallization time-temperature-transformation (TTT) diagrams are determined for two bulk metallic glass forming alloys, i.e. $\mathrm{Au}_{49} \mathrm{Ag}_{5.5} \mathrm{Pd}_{2.3} \mathrm{Cu}_{26.9} \mathrm{Si}_{16.3}$ (Au-BMG) and $\mathrm{Au}_{51.6} \mathrm{Ag}_{5.8} \mathrm{Pd}_{2.4} \mathrm{Cu}_{20.2} \mathrm{Ga}_{6.7} \mathrm{Si}_{13.3}$ (AuGa-BMG). 
The Au-BMG system shows a more 'conventional' nose shape of the TTT-diagram, while for the AuGa-BMG a, to our knowledge not yet for metallic systems reported, doublenose shape was observed, featuring a tremendously fast lowtemperature crystallization process.

Despite the fact that the overall tendency of the CCR observed in FDSC is in line with the trend of the macroscopical critical casting thickness $d_{\mathrm{c}}$, the CCR in FDSC does not allow a direct calculation of the critical thickness for these systems based on current models for the given system. Therefore a direct quantitative connection with the macroscopic process of glass formation during e.g. a copper mold casting process, is rather difficult.

In contrast, the use of the minimal nose time $\tau_{x}^{*}$ determined in isothermal crystallization experiments outgoing from the liquid state, paired with the empirical formula of Johnson et al [37] showed a very good consensus with the macroscopic data of the critical thicknesses from copper mold casting experiments. Even in the scenario of a complete change in shape of the crystallization nose, as observed for the AuGa-BMG system, the use of the lowest $\tau_{x}^{*}$ did provide a rather good estimation of the GFA. In addition an adequate alignment of the crystallization times at short timescales obtained in FDSC with the larger timescales acquired in conventional DSC was shown.

The simple shape of the crystallization nose of the Au-BMG also allowed for the determination of the interfacial energy $\gamma_{1-x}$ based on the JMAK-model for nucleation and growth. Here a rather low $\gamma_{1-x}$ value, similar to a ZrTiCuNiBe BMG, was observed for the Au-BMG.

Due to the mentioned untypical shape for the AuGa-BMG, this analysis does not provide sound data with satisfying convergence to the applied model. This can be traced back to the lack of an adequate kinetic and thermodynamic description of the system that does take the two observed different crystallization behaviors into account. But, with the new and still improving technique of flash calorimetry a vital tool is given to further analyze such fast crystallization processes in more detail and come up with new methodology as well as a refinement of the used models in the near future.

\section{Acknowledgments}

The authors want to thank A Kuball, B Bochtler and S Hechler for collaboration and fruitful discussions concerning the topic. We further want to express our gratitude to $C$ Hafner $\mathrm{GmbH}$ + Co.KG and Heraeus Holding $\mathrm{GmbH}$ for the gold, palladium and silver supply.

\section{ORCID iDs}

Nico Neuber (D) https://orcid.org/0000-0002-9912-5764

Maximilian Frey (D) https://orcid.org/0000-0001-8602-721X

Oliver Gross (D) https://orcid.org/0000-0003-4281-6182

\section{References}

[1] Schroers J, Lohwongwatana B, Johnson W L and Peker A 2005 Gold based bulk metallic glass Appl. Phys. Lett. 87061912

[2] Eisenbart M, Klotz U E, Busch R and Gallino I 2014 On the abnormal room temperature tarnishing of an 18 karat gold bulk metallic glass alloy J. Alloys Compd. 615 S118-22

[3] Eisenbart M, Klotz U E, Busch R and Gallino I 2014 A colourimetric and microstructural study of the tarnishing of goldbased bulk metallic glasses Corros. Sci. 85 258-69

[4] Fiore G and Battezzati L 2008 Developing Au-based amorphous alloys Rev. Adv. Mater. Sci. 18 190-2

[5] Guo H, Zhang W, Qin C, Qiang J, Chen M and Inoue A 2009 Glass-forming ability and properties of new Au-based glassy alloys with low $\mathrm{Au}$ concentrations Mater. Trans. 50 1290-3

[6] Gross O, Eisenbart M, Schmitt L-Y Y, Neuber N, Ciftci L, Klotz U E, Busch R and Gallino I 2018 Development of novel 18-karat, premium-white gold bulk metallic glasses with improved tarnishing resistance Mater. Des. 140 495-504

[7] Neuber N, Gross O, Eisenbart M, Heiss A, Klotz U E, Best J P, Polyakov M N, Michler J, Busch R and Gallino I 2019 The role of $\mathrm{Ga}$ addition on the thermodynamics, kinetics, and tarnishing properties of the $\mathrm{Au}-\mathrm{Ag}-\mathrm{Pd}-\mathrm{Cu}-\mathrm{Si}$ bulk metallic glass forming system Acta Mater. 165 315-26

[8] Kelton K F and Greer A L 2010 Nucleation in Condensed Matter (Amsterdam: Elsevier)

[9] Christian J W 2003 The Theory of Transformations in Metals and Alloys (Oxford: Newnes)

[10] Gross O, Riegler S S, Stolpe M, Bochtler B, Kuball A, Hechler S, Busch R and Gallino I 2017 On the high glass-forming ability of Pt-Cu-Ni/Co-P-based liquids Acta Mater. 141 109-19

[11] Hays C C and Johnson W L I1999 Undercooling of bulk metallic glasses processed by electrostatic levitation J. Non-Cryst. Solids 250-252 596-600

[12] Hays C C, Kim C P and Johnson W L 1999 Large supercooled liquid region and phase separation in the $\mathrm{Zr}-\mathrm{Ti}-\mathrm{Ni}-\mathrm{Cu}-\mathrm{Be}$ bulk metallic glasses Appl. Phys. Lett. 75 1089-91

[13] Schroers J, Johnson W L and Busch R 2000 Crystallization kinetics of the bulk-glass-forming $\mathrm{Pd}_{43} \mathrm{Ni}_{10} \mathrm{Cu}_{27} \mathrm{P}_{20}$ melt Appl. Phys. Lett. 77 1158-60

[14] Löffler J F, Schroers J and Johnson W L 2000 Time-temperature-transformation diagram and microstructures of bulk glass forming $\mathrm{Pd}_{40} \mathrm{Cu}_{30} \mathrm{Ni}_{10} \mathrm{P}_{20}$ Appl. Phys. Lett. 77 681-3

[15] Schroers J, Wu Y, Busch R and Johnson W L 2001 Transition from nucleation controlled to growth controlled crystallization in $\mathrm{Pd}_{43} \mathrm{Ni}_{10} \mathrm{Cu}_{27} \mathrm{P}_{20}$ melts Acta Mater. 49 2773-81

[16] Kim Y J, Busch R, Johnson W L, Rulison A J and Rhim W K 1996 Experimental determination of a time-temperature-transformation diagram of the undercooled $\mathrm{Zr}$ 41.2Ti13.8Cu12.5Ni10.0Be22.5 alloy using the containerless electrostatic levitation processing technique Appl. Phys. Lett. 68 1057-9

[17] Pogatscher S, Uggowitzer P J and Löffler J F 2014 In-situ probing of metallic glass formation and crystallization upon heating and cooling via fast differential scanning calorimetry Appl. Phys. Lett. 104251908

[18] Schawe J E K and Löffler J F 2019 Existence of multiple critical cooling rates which generate different types of monolithic metallic glass Nat. Commun. 10 1-10

[19] Schawe J E K, Vermeulen P A and Van Drongelen M 2015 Two processes of $\alpha$-phase formation in polypropylene at high supercooling Thermochim. Acta 616 87-91

[20] Mukherjee S, Zhou Z, Schroers J, Johnson W L and Rhim W K 2004 Overheating threshold and its effect on timetemperature-transformation diagrams of zirconium based bulk metallic glasses Appl. Phys. Lett. 84 5010-2 
[21] Pogatscher S, Leutenegger D, Hagmann A, Uggowitzer P J and Löffler J F 2015 Reprint of: Characterization of bulk metallic glasses via fast differential scanning calorimetry Thermochim. Acta 603 46-52

[22] Wang J Q, Shen Y, Perepezko J H and Ediger M D 2016 Increasing the kinetic stability of bulk metallic glasses Acta Mater. $10425-32$

[23] Lin X H and Johnson W L 1995 Formation of Ti-Zr-Cu-Ni bulk metallic glasses J. Appl. Phys. 78 6514-9

[24] Evenson Z 2012 On the Thermodynamic and Kinetic Properties of Bulk Glass Forming Metallic Systems (Saarbrücken: Saarlandes) doi:10.22028/D291-22851

[25] Schawe J E K 2015 Measurement of the thermal glass transition of polystyrene in a cooling rate range of more than six decades Thermochim. Acta 603 128-34

[26] Uhlmann D R 1972 A Kinetic Treatment of Glass Transition J. Non-Cryst. Solids 7 337-48

[27] Uhlmann D R 1977 Glass formation J. Non-Cryst. Solids 25 $42-85$

[28] Angell C A 1995 Formation of glasses from liquids and biopolymers Science 267 1924-35

[29] Hechler S, Ruta B, Stolpe M, Pineda E, Evenson Z, Gross $\mathrm{O}$ and Hembree W 2017 Liquid-liquid transition revealed by quasi-static cooling of an ultra-viscous metallic liquid (arXiv:1704.06703)

[30] Gallino I, Cangialosi D, Evenson Z, Schmitt L, Hechler S, Stolpe M and Ruta B 2018 Hierarchical aging pathways and reversible fragile-to-strong transition upon annealing of a metallic glass former Acta Mater. 144 400-10

[31] Bai F X, Yao J H, Wang Y X, Pan J and Li Y 2017 Crystallization kinetics of an Au-based metallic glass upon ultrafast heating and cooling Scr. Mater. 132 58-62

[32] Gross O 2018 Precious Metal Based Bulk Glass-Forming Liquids: Development, Thermodynamics, Kinetics and Structure (Saarbrücken: Diss. Saarl. Univ) doi:10.22028/D291-27993

[33] Masuhr A, Waniuk T A, Busch R and Johnson W L 1999 Time scales for viscous flow, atomic transport, and crystallization in the liquid and supercooled liquid states of $\mathrm{Zr} 41.2 \mathrm{Ti13} .8 \mathrm{Cu} 12.5 \mathrm{Ni10.0Be22.5}$ Phys. Rev. Lett. 82 2290-3

[34] Gross O, Riegler S S, Stolpe M, Bochtler B, Kuball A, Hechler S, Busch R and Gallino I 2017 On the high glassforming ability of Pt-Cu-Ni/Co-P-based liquids Acta Mater. 141 109-19

[35] Legg B A, Schroers J and Busch R 2007 Thermodynamics, kinetics, and crystallization of Pt57.3Cu14.6Ni5.3P22.8 bulk metallic glass Acta Mater. 55 1109-16

[36] Gallino I, Schroers J and Busch R 2010 Kinetic and thermodynamic studies of the fragility of bulk metallic glass forming liquids J. Appl. Phys. 108063501

[37] Johnson W L, Na J H and Demetriou M D 2016 Quantifying the origin of metallic glass formation Nat. Commun. 710313 